\title{
Nós versus eles: ódio biopolítico contra a população LGBT no Twitter de Marco Feliciano
}

\author{
We versus them: Biopolitical hate against LGBT population on Marco \\ Feliciano's Twitter
}

\section{Nosotros versus ellos: el odio biopolítico contra la población LGBT en el Twitter de Marco Feliciano}

Aline Roes Dalmolin ${ }^{1, a}$

aline.dalmolin@ufsm.br | http://orcid.org/o0oo-0003-4413-0061

Marina Martinuzzi Castilho ${ }^{1, b}$

mari.castilho@gmail.com | http://orcid.org/0000-0003-1304-4443

Márcia Zanin Feliciani ${ }^{1, c}$

marciazaninfeliciani@gmail.com | http://orcid.org/oooo-0001-7324-9075

${ }^{1}$ Universidade Federal de Santa Maria. Santa Maria, RS, Brasil.

a Doutorado em Ciências da Comunicação pela Universidade do Vale do Rio dos Sinos.

b Mestrado em Ciências da Comunicação pela Universidade Federal de Santa Maria.

'Graduação em Comunicação Social (Produção Editorial) pela Universidade Federal de Santa Maria.

\section{Resumo}

Neste artigo, objetivamos analisar o ativismo do pastor e deputado federal brasileiro Marco Feliciano na contrariedade a propostas de lei e pautas relacionadas à sexualidade e ao gênero, a exemplo do Projeto de Lei $\mathrm{n}^{\circ}$ 122/2006, mais conhecido como 'anti-homofobia'. Para tanto, analisamos as postagens realizadas por Feliciano em sua conta oficial no Twitter durante o ano de 2011. A metodologia utilizada é a análise discursiva, compreendendo a atuação do pastor como desencadeadora de um tensionamento entre os campos político, religioso e midiático. Conclui-se, a partir da análise, que as postagens de Marco Feliciano expressam ódio biopolítico contra os LGBT, vistos como populações a serem eliminadas e que ameaçam a ordem heterossexual cisgênero vigente.

Palavras-chave: Mídia e religião; Mídias sociais; Marco Feliciano; Twitter; Sexualidade; LGBT; Ódio biopolítico. 


\begin{abstract}
In this article, we aim to analyze the activism of Brazilian pastor and federal deputy Marco Feliciano in order to offer opposition to legislation and guidelines related to sexuality and gender, such as bill $n^{0} 122 / 2006$, better known as 'anti-homophobia'. In order to do so, we analyze the messages posted by Feliciano in his official account on Twitter during the year 2011. The methodology used is the discursive analysis, including the pastor acting as triggering a tension between the political, religious and media fields. It is concluded from the analysis that the posts of Marco Feliciano express biopolitical hate against the LGBT, seen as populations to be eliminated and that threaten the current cisgender heterosexual order.
\end{abstract}

Keywords: Media and religion; Social media; Marco Feliciano; Twitter; Sexuality; LGBT; Biopolitical hate.

\title{
Resumen
}

En este artículo, objetivamos analizar el activismo del pastor y diputado federal brasileño Marco Feliciano para combatir propuestas de ley y pautas relacionadas a sexualidad y género, a ejemplo del proyecto de ley 122/2006, más conocido como 'anti-homofobia'. Para llevar el objetivo a cabo, analizamos las mensajes publicadas por Feliciano en su cuenta oficial en Twitter durante el año 2011. La metodología utilizada es el análisis discursivo, comprendiendo la actuación del pastor como desencadenadora de una tensión entre los campos políticos, religioso y mediático. Se concluye, a partir del análisis, que las publicaciones de Marco Feliciano expresan odio biopolítico contra los LGBT, vistos como poblaciones a eliminar y que amenazan el orden heterosexual cisgénero vigente.

Palabras clave: Medios y religión; Redes sociales; Marco Feliciano; Twitter; Sexualidad; LGBT; Odio biopolítico.

INFORMAÇÕES DO ARTIGO

Este texto compõe o dossiê 40 anos do movimento LGBT no Brasil: comunicação, saúde e direitos humanos.

Contribuição dos autores: Todos os autores se envolveram igualmente nas etapas de construção do trabalho: concepção e desenho do estudo; aquisição, análise ou interpretação dos dados; redação do manuscrito e revisão crítica do conteúdo intelectual.

Declaração de conflito de interesses: não há.

Fontes de financiamento: Programa Institucional de Bolsas de Iniciação Científica (Pibic)/Conselho Nacional de Desenvolvimento Científico e Tecnológico (CNPq).

Considerações éticas: artigo faz parte do projeto "Moralidades contemporâneas, fundamentalismos pós-modernos: a circulação dos discursos de ódio na mídia", registrado no Portal de Projetos da UFSM sob n 039739 e aprovado pelo Conselho de Pesquisa do Centro de Ciências Sociais e Humanas/UFSM.

Agradecimentos/Contribuições adicionais: não há.

Histórico do artigo: submetido: 08 jan. 2019 | aceito: 23 maio 2019 | publicado: 28 jun. 2019.

Apresentação anterior: não houve.

Licença CC BY-NC atribuição não comercial. Com essa licença é permitido acessar, baixar (download), copiar, imprimir, compartilhar, reutilizar e distribuir os artigos, desde que para uso não comercial e com a citação da fonte, conferindo os devidos créditos de autoria e menção à Reciis. Nesses casos, nenhuma permissão é necessária por parte dos autores ou dos editores. 


\section{Introdução}

Nas últimas décadas, as pautas do movimento LGBT ${ }^{\mathrm{i}}$ vêm se manifestando com intensidade nos âmbitos social e político brasileiros. Por outro lado, em reação a este contexto, destaca-se o recrudescimento de discursos conservadores e simbolicamente violentos, principalmente entre as publicações e comentários nas redes sociais. A partir de movimentos ainda anteriores às eleições de 2018, vimos uma diversidade de posicionamentos que pregam a expressão de comportamentos políticos divergentes enquanto 'desvios morais' e 'ameaças' aos 'valores tradicionais' do 'cidadão de bem' e da 'família tradicional brasileira'. Estas opiniões, assim identificadas, exemplificam a presença de um discurso de ódio biopolítico envolvido em debates públicos realizados por atores sociais visivelmente adversários nesses espaços de discussão.

A expressão desse ativismo pode ser observada no entrecruzamento entre os campos midiático, político e religioso, notadamente pelo engajamento de setores evangélicos na política e da propagação de seu ideário fundamentalista e conservador por intermédio da mídia. No Congresso Nacional, esses grupos atuam de forma reacionária, confrontando propostas que consideram contrárias a seus valores e à sua moral' ${ }^{1}$ Essa atuação em nome do que eles defendem como pauta de uma 'maioria moral' pode ser reportada ao momento histórico das eleições dos parlamentares para a Assembleia Constituinte de 1988, e vem crescendo em participação no cenário político nos últimos anos a partir do gradativo aumento da chamada 'bancada evangélica'.

Um dos componentes que se destacam nessa bancada é o deputado federal de São Paulo e pastor da igreja evangélica Assembleia de Deus Catedral do Avivamento, Marco Feliciano. Este vem dedicando seus mandatos parlamentares e sua atuação midiática à defesa de um modelo tradicional de família e de causas conservadoras, principalmente no que tange a propostas de interesse da população LGBT. Nacionalmente reconhecido enquanto figura pública a partir de sua atuação parlamentar e religiosa, ele destaca-se por uma forte presença nas redes sociais e envolvimento em algumas polêmicas midiáticas.

O presente artigo traz uma análise das publicações feitas por Marco Feliciano em seu perfil oficial no Twitter durante o ano de 2011. A união estável, a adoção de crianças e a concessão de pensão por morte em caso de falecimento do parceiro em se tratando de casais homossexuais, além da tentativa do Governo Federal de distribuir materiais informativos sobre sexualidade e gênero, episódio pejorativamente conhecido como 'kit gay', foram iniciativas bastante criticadas por Feliciano naquele ano, tanto na tribuna quanto nas redes sociais. A base argumentativa era praticamente a mesma com relação a todas elas: tais projetos, para o deputado, feriam o modelo tradicional de família expresso na Bíblia Sagrada e na Constituição Federal, assim entendida enquanto a união entre homem, mulher e filhos(as).

A escolha pelo recorte em 2011 justifica-se pelo fato de que naquele ano intensificou-se o debate sobre os LGBT no Congresso Nacional e na sociedade brasileira em função do Projeto de Lei da Câmara (foi só em 2011, quando passou a tramitar no Senado Federal, que a Lei se tornou alvo de grandes debates PLC) no 122/2006, mais conhecido como 'Lei Anti-Homofobia'. Apesar da proposta surgir em 2006 $6^{\mathrm{ii}}$, e repercussões por conservadores. Nesse período, Feliciano e outras lideranças dos campos religioso e político promoveram uma campanha significativa, em especial nas redes sociais, para impedir que o Projeto se tornasse lei. Além disso, trata-se do ano no qual Feliciano inicia seu mandato parlamentar, empenhando-se fortemente para imprimir uma marca em sua atuação na defesa dos valores conservadores e de uma pauta moral estrita. $\mathrm{O}$ intenso ativismo religioso e midiático do pastor e deputado, por sua vez, fundamenta a escolha do enfoque

\footnotetext{
i Ao utilizarmos a sigla LGBT expressa por Lésbicas, Gays, Bissexuais, Travestis e Transexuais nos referimos à manifestação mais utilizada entre os próprios atores e grupos (institucionalizados ou não) do movimento ativista no Brasil. No entanto, também compreendemos e nos apoiamos na constante luta inclusiva que outros indivíduos e segmentos imprimem ao reivindicar suas identidades de gênero e orientações sexuais nesta 'abreviatura', que também faz referência a ações políticas e sociais.

ii O projeto, de autoria da então deputada federal Iara Bernardi (PT-SP), visava suprir a lacuna existente na legislação brasileira com relação à discriminação motivada por questões sexuais e/ou de gênero, acrescentando esses pontos à Lei no $7.716 / 1989$ (que criminaliza o preconceito decorrente de raça ou cor).
} 
da análise em um de seus perfis de redes sociais ${ }^{\text {iii }}$. Naquele momento, Feliciano elege o Twitter como um dos principais campos de batalha em torno dessas pautas, dirigindo-se de forma direta a seus fiéis e eleitores e demarcando suas percepções por meio do discurso.

O presente estudo observa como as manifestações discursivas do pastor ganham legitimidade e visibilidade com as mídias sociais. Mesmo designando uma opinião singular, realizada em uma de suas contas oficiais nessas mídias, é possível inferir a partir de suas postagens uma defesa de interesses bem delineada em relação às pessoas LGBT. Ao realizar a análise do discurso de um conjunto de postagens do pastor e deputado no Twitter, observa-se como ele aciona discursos de controle sobre condutas privadas.

Por outro lado, ressalta-se a atuação de Marco Feliciano no horizonte de uma sociedade em vias de midiatização, caracterizada por transformações institucionais em curso que implicam na atual interseção entre os campos político, religioso e midiático brasileiros. O estudo torna-se possível e, ao mesmo tempo complexificado, a partir da identificação de um ethos midiatizado ${ }^{3}$ próprio que demarca a atuação e a presença de Marco Feliciano entre as três esferas mencionadas. Buscam-se analisar evidências midiáticas que demonstram a atuação de um importante líder evangélico e político presente hoje na sociedade brasileira.

O trabalho aqui apresentado traz, portanto, um caminho propositivo para a compreensão de importantes eventos contemporâneos. Ao reconhecer a visível ascensão do grupo evangélico atrelada a discursos conservadores, também identifica-se uma maior atuação desse setor junto à mobilização política realizada nas redes sociais, como observado de forma bastante intensiva nos últimos processos eleitorais, em especial o de 2018. Ao explorar as ações e discursos de Marco Feliciano por meio dessas redes, possibilita-se compreender como a midiatização é capaz de interpelar e transformar experiências dos campos religioso e político.

A partir da análise, enfatiza-se a reprodução de um discurso de ódio de caráter biopolítico, direcionado por Marco Feliciano a seus adversários, aqui representados pela sigla LGBT. Vinculando sua ação midiatizada ao comportamento de ativista político, investiga-se de que forma o pastor e deputado federal produz opiniões que manifestam termos de cunho biológico e racista em referência às oposições emergentes de debates públicos e políticos. A apuração desses discursos delineia, igualmente, o empreendimento do pastor e deputado em refutar mudanças institucionais requeridas por pessoas e coletivos considerados marginais na abrangência das políticas públicas existentes hoje em nosso país.

\section{Fundamentação teórica: a qualificação da vida e a dimensão do ódio biopolítico}

Propomos o conceito de "ódio biopolítico" a partir de uma revisão teórica dos trabalhos de Foucault ${ }^{4-5}$ e Agamben ${ }^{6}$. Trabalharemos nesta seção algumas das proposições desses autores sobre o conceito de biopolítica.

O filósofo francês Michel Foucault (1926-1984) tornou-se mundialmente conhecido por estudar os dispositivos de poder. $\mathrm{O}$ autor teceu suas considerações a partir de um apanhado histórico do que julgou serem as três principais formas de exercício do poder vigentes na história da humanidade: a soberania, a disciplina e a biopolítica. No que chama de teoria clássica da soberania, o direito sobre a vida e, principalmente, sobre a morte dos súditos era delegado à figura do soberano. Segundo Foucault ${ }^{4,5}$, os indivíduos não podiam ser considerados nem vivos nem mortos, mas neutros: seu destino era definido pelo governante, que decidia a quem seria permitido viver e quem deveria morrer. "O poder era, antes de tudo, nesse tipo de sociedade, direito de apreensão das coisas, do tempo, dos corpos e, finalmente, da vida; culminava com o privilégio de se apoderar da vida para suprimi-la"4.

Pode-se dizer que a morte era, nessa forma de exercício do poder, mais importante do que a vida. Do ponto de vista dos súditos porque ela representava o momento em que "libertavam-se"4 do poder do soberano, escapando do seu alcance; e deste porque era designando um indivíduo à morte que ele demonstrava a

iii O número de seguidores de suas redes oficiais, atualmente, é constituído de 4,4 milhões no Facebook, 1,4 milhão no Instagram e 538 mil no Twitter, além de 166 mil inscritos em seu canal do Youtube. Dados obtidos em 07/02/2018. 
amplitude de seu poder. "O soberano só exerce, no caso, seu direito sobre a vida, exercendo seu direito de matar ou contendo-o; só marca seu poder sobre a vida pela morte que tem condições de exigir. O direito que é formulado como 'de vida e morte' é, de fato, o direito de causar a morte ou de deixar viver"4.

De uma maneira ou de outra, nessa forma de exercício do poder "[...] a vida e a morte não são consideradas como fenômenos naturais, exteriores ao campo político - elas se vinculam ao soberano, ao poder, ao direito" . Foi assim durante muito tempo (mais precisamente até o século XVII), mas esse sistema mostrou-se incapaz de acompanhar a expansão acelerada das populações, que se deu muito em prol da sua saída do campo para a cidade em consequência do desenvolvimento do capitalismo. Este, por sua vez, necessitava de uma forma de poder que fosse capaz de cobrir a totalidade da vida, tanto no âmbito individual quanto no coletivo. Além disso, uma 'provocação' que começou a circular na época (elaborada, principalmente, por juristas) passou a questionar a centralidade dada à morte no exercício do poder soberano.

"Eles [os súditos] o fazem [elegem um soberano], por conseguinte, para proteger a vida. É para poder viver que constituem um soberano. E, nesta medida, a vida pode efetivamente entrar nos direitos do soberano? E não pode o soberano reclamar efetivamente de seus súditos o direito de exercer sobre eles o poder de vida e de morte, ou seja, pura e simplesmente, o poder de matá-los? Não deve a vida ficar fora do contrato, na medida em que ela é que foi o motivo primordial, inicial e fundamental do contrato?"5.

É nesse contexto, então, que se passa a implantar o que Foucault ${ }^{4,5}$ chama de biopoder - que se materializa por meio das tecnologias da disciplina e da biopolítica. Enquanto o objeto da disciplina é o indivíduo, o corpo enquanto máquina que deve ser otimizada, 'docilizada' e controlada, o da biopolítica é a população, o corpo enquanto espécie: visa-se, por intermédio de uma série de medidas de Estado, melhorar a qualidade de vida do grupo em questão. Segundo Pelbart”, o diferencial com relação à soberania é que "[...] nesse novo regime o poder é destinado a produzir forças e as fazer crescer e ordená-las, mais do que a barrá-las ou destruí-las. Gerir a vida, mais do que exigir a morte"'.

Os princípios disciplinares são postos em prática primeiro, no final do século XVII. Nesse tipo de organização, o poder não se exerce de forma centralizada, mas difundido entre as instituições sociais - como escolas, hospitais e prisões. Atua, assim, “[...] mediante todo um sistema de vigilância, de hierarquias, de inspeções, de escriturações, de relatórios" ${ }^{\prime}$, visando controlar e otimizar a atividade produtiva dos cidadãos comuns e corrigir os desviantes.

Já a biopolítica surge na passagem do século XVIII para o XIX. Trata-se do momento em que os Estados tomam para si a responsabilidade de controle da vida das populações - não na sua condição de indivíduos, mas de espécie. A partir desse momento, "[...] a vida e seus mecanismos entram nos cálculos explícitos do poder e saber, enquanto estes se tornam agentes de transformação da vida. A espécie torna-se a grande variável nas próprias estratégias políticas"'.

Isso é executado a partir de uma série de medidas, que se dão no sentido de: a) controlar as taxas de fecundidade, natalidade, longevidade e mortalidade; b) evitar as endemias - que, diferentemente das epidemias, que comumente culminavam em morte, são doenças que impossibilitam temporariamente os indivíduos de produzir; c) lidar com a invalidez, tanto nos casos de velhice quanto nos de limitações físicas e/ou mentais de nascença ou adquiridas no decorrer da vida; d) dar atenção às relações das populações com os ambientes em que vivem, especialmente no contexto de desenvolvimento das cidades, entre outras ações.

Por se voltarem para níveis diferentes (uma para o corpo-indivíduo e outra para o corpo-espécie), a disciplina e a biopolítica podem dialogar entre si. Esse diálogo é visível principalmente no que tange à sexualidade: ao mesmo tempo que se refere ao biológico, às relações que permitem a procriação e, logo, à preservação da espécie humana, também é atravessada por regras sociais que dizem quais comportamentos são e/ou não são adequados para uma determinada situação. Esta percepção é um elemento central a fim de encaminharmos as proposições de análise.

Essas regras, então, se caracterizam não por estarem registradas, mas por serem consensos pré-reflexivos assimilados e reproduzidos pelos sujeitos; Foucault ${ }^{4,5}$ as chama de normas e caracteriza as sociedades nas quais os entrelaçamentos entre disciplina e biopolítica se verificam como sociedades de normalização. 
As normas permitem que se adotem padrões não só de atitudes como também de pessoas, de corpos; definem, assim, quais os seres vivos qualificados e, portanto, aptos a dar continuidade à espécie e quais os que, pelo bem dos demais, devem ser eliminados.

Esse "[...] corte entre o que deve viver e o que deve morrer"5 definido a partir da norma é o que Foucault classifica como racismo ${ }^{\text {iv }}$. Ele é tão forte a ponto de ser utilizado como justificativa para que os Estados deem início a guerras. Isto é: para cumprir efetivamente sua função de preservação da vida, um Estado deve estar preparado para exterminar todos aqueles que representem um perigo a ela, seja externo ou interno.

O autor afirma que "[...] esse formidável poder de morte - e talvez seja o que lhe empresta uma parte da força e do cinismo com que levou tão longe seus próprios limites - apresenta-se agora como o complemento de um poder que se exerce, positivamente, sobre a vida, que empreende sua gestão, sua majoração, sua multiplicação, o exercício, sobre ela, de controles precisos e regulações de conjunto. As guerras já não se tratam em nome do soberano a ser defendido; travam-se em nome da existência de todos; populações inteiras são levadas à destruição mútua em nome da necessidade de viver. Os massacres se tornaram vitais"4.

Agamben ${ }^{6}$ parte da concepção de racismo de Foucault para explorar o que, segundo ele, seria o paradigma biopolítico da modernidade: a experiência nazista dos campos de concentração. Entretanto, o autor vê a distribuição e o exercício do poder de uma forma um pouco diferente. Para ele, o fato de o direcionamento do poder do Estado para a preservação de algumas vidas ter permitido que outras fossem violentamente expostas à morte é prova de que o poder soberano não se enfraqueceu com a emergência da biopolítica, pelo contrário: passou a se exercer com muito mais força a partir dela, mas de maneira diferenciada.

Além disso, para Agamben 6 , a manifestação desta “soberania biopolítica” não se daria só com relação a raças, mas também a indivíduos em especial - os quais ele chama de homo sacer. Trata-se de uma figura jurídica histórica considerada matável e insacrificável. Matável porque, apesar de não ser oficialmente permitido assassiná-lo, quem o fizesse não seria condenado por homicídio; e insacrificável porque, normalmente, era qualificado como homo sacer aquele que cometia algum delito e que, por isso, tornava-se indigno de ser sacrificado aos deuses. Era, portanto, uma vida destituída de seu valor: para os demais, era indiferente se vivesse ou morresse.

Essas vidas, que Agamben ${ }^{6}$ também chama de "vidas nuas", são intimamente ligadas ao soberano, visto que é ele quem as define como tais e as expõe à possibilidade da morte. Hoje, entretanto, o soberano não é mais aquele de que Foucault falava quando dissertava sobre a teoria clássica da soberania, mas sim qualquer pessoa que não seja classificada como uma "vida nua"6 e que possa agir de forma soberana com relação a ela, ou seja: aquela que tem o poder de matar. "Nos dois limites extremos do ordenamento, soberano e homo sacer apresentam duas figuras simétricas, que têm a mesma estrutura e são correlatas, no sentido de que soberano é aquele em relação ao qual todos os homens são potencialmente homines sacri e homo sacer é aquele em relação ao qual todos os homens agem como soberanos".

Ao mesmo tempo que a biopolítica colocou a vida no centro do interesse político, permitiu que outras vidas (as que, de alguma maneira, representavam um perigo para ela), fossem designadas à morte. Ao qualificarse estas outras vidas como 'matáveis', estar-se-ia exercendo o poder soberano - ou seja, destituindo-as de seu caráter político, tornando-as vidas nuas. Foi exatamente o que o nazismo fez. "O hebreu sob o nazismo é o referente negativo privilegiado da nova soberania biopolítica e, como tal, um caso flagrante de homo sacer, no sentido de vida matável e insacrificável. O seu assassinato não constitui, portanto, como veremos, nem uma execução capital, nem um sacrifício, mas apenas a realização de uma mera 'matabilidade' que é inerente à condição de hebreu como tal”’

A partir das leituras de Foucault ${ }^{4,5}$ e Agamben ${ }^{6}$, propõe-se enquanto ódio biopolítico aquele motivado por características biológicas ou, no mínimo, inerentes aos indivíduos - como o gênero, a orientação sexual, a cor da pele, o lugar de origem, a situação socioeconômica, o posicionamento político etc. Aquele que sente o ódio

iv É preciso destacar que a noção de racismo, para o filósofo francês, diferencia-se de como é compreendido pelo senso comum, relacionado apenas à cor da pele. 
reconhece o outro não só como diferente, mas como uma ameaça para si e para o grupo ao qual pertence, o que o faz procurar maneiras de eliminá-lo - se não fisicamente, pelo menos de forma simbólica e/ou discursiva.

Esse desejo de eliminação do outro mediante o discurso se aproxima dos conceitos de racismo e de exercício do poder soberano sobre a vida nua, pensada, respectivamente por Foucault ${ }^{4,5}$ e Agamben ${ }^{6}$. Ao englobar o trabalho dos dois autores, não se desconsideram as diferenças entre eles, uma vez que o autor italiano reposiciona a biopolítica na perspectiva do poder soberano. Conforme atesta Bazzicalupo ${ }^{8}$, é possível compreender o pensamento de Agamben ${ }^{6}$ como uma "correção de rumo" no modo foucaultiano de pensar a biopolítica.

A expressão 'discurso de ódio', comumente utilizada, mostrou-se problemática por dar margem a interpretações diversas. Como podemos classificar um discurso como dotado de ódio se, muitas vezes, ele aparece disfarçado ou suavizado de forma a não aparentar ser o que é? Como definir tais discursos de tal forma se quem o profere o faz assegurado pelo princípio da liberdade de expressão, que, da mesma forma que a culpabilização por atos discriminatórios, é assegurado pela Constituição? São questões às quais não conseguimos responder de maneira satisfatória.

As teorias de Foucault ${ }^{4,5}$ e Agamben ${ }^{6}$ falam de um racismo extremo, que é legitimado pelo Estado e leva à morte dos 'inimigos' - o que, no contexto midiatizado em que vivemos, se dá de forma diferente. Hoje, a normalização, o racismo e a designação das vidas nuas manifestam-se também de formas mais sutis - sendo os discursos mascarados por justificativas religiosas e políticas, em especial os publicados em circulação nas redes sociais, ou em uma delas. Veremos na sequência como esse ódio biopolítico é mobilizado nas postagens de Marco Feliciano.

\section{Metodologia}

A metodologia empregada consiste na análise discursiva das postagens, voltando-se para o mapeamento dos sentidos e das designações utilizadas no texto 9 . Ao enxergarmos nuances discursivas similares, publicizadas pelos tweets de Marco Feliciano, reconhecemos a centralidade do argumento que envolve a 'defesa da família', concomitantemente interpelada por posicionamentos morais e de cunho religioso. Ao constatar as intensas disputas que envolveram o debate em torno do $\mathrm{PLCn}^{\circ}$ 122, verifica-se um conteúdo moral fortemente pregado em torno de um ideário cristão. Este aspecto imprime aos políticos-religiosos a formação de uma verdadeira 'cruzada', em que os movimentos LGBT e feminista são considerados 'inimigos e destruidores’ da família brasileira.

Para a construção do corpus, foram elencadas todas as postagens realizadas por Marco Feliciano em seu perfil oficial no Twitter no ano de 2011 por meio do mecanismo de busca avançada da rede social. Destas, foram separados os tweets que denotavam o posicionamento do deputado a respeito do movimento LGBT e suas pautas. A seleção das postagens não se deu com base na busca por palavras-chave específicas, mas de uma análise discursiva e contextual de cada um dos tweets. O recorte abarca apenas as postagens originais de Feliciano, desconsiderando retweets e respostas dadas ao pastor por outros usuários. Quando mencionados por Feliciano em seus tweets, os nomes destes foram apagados por questões de ética na pesquisa.

A análise do discurso possui como um de seus princípios a não exaustividade da análise em seu sentido horizontal, uma vez que, ao contrário, se orienta para extrair a verticalidade de seus sentidos. Ou seja, a análise busca compreender os sentidos em sua profundidade, ampliando e complexificando sua expressividade em uma determinada conjuntura ${ }^{10}$. Portanto, apresenta-se neste artigo uma pesquisa qualitativa a partir dessas postagens, presentes no texto que mostra printscreens da página oficial de Feliciano no Twitter, seguidas pela análise discursiva e suas principais designações.

As designações, em análise de discurso, podem ser compreendidas como modos pelos quais um enunciador (aquele que diz no texto) apresenta o referente em um determinado enunciado (aquilo que é dito). A leitura

v Disponível em: https://twitter.com/marcofeliciano. 
das designações busca compreender as estratégias discursivas pelas quais o enunciador passa, ao coenunciador (aquele que lê o que o enunciador diz), as instruções necessárias para identificar os referentes num determinado contexto9. Ou seja, no caso das redes sociais, evidencia aos interagentes uma espécie de 'chave de leitura', promovendo mecanismos de identificação entre contextos e referentes. Demonstraremos, a seguir, as principais denominações utilizadas por Feliciano para referir-se ao movimento LGBT - bem como suas implicações.

\section{Resultados e discussão}

Os tweets a seguir ilustram as principais designações encontradas. Na sequência, no item referente à discussão, observaremos como essas podem ser compreendidas como expressão de ódio biopolítico aos LGBT.

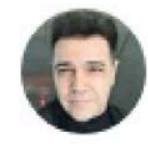

\section{Marco Feliciano @ @marcofeliciano.4 May 2011}

Replying to@

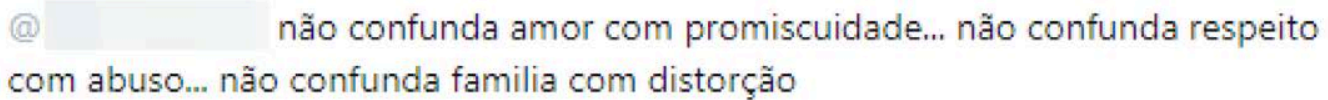

6 Translate Tweet

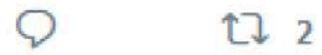

Figura 1 - Marco Feliciano: Post do dia 4 de maio de 2011

Fonte: Twitter (2018).

Na Figura 1, em conversa com um usuário, Feliciano caracteriza o amor entre um casal homoafetivo como 'promiscuidade', seu desejo por mais respeito como 'abuso' e os modelos de família divergentes do tradicional como 'distorção'. Ou seja: para ele, um relacionamento entre um casal homossexual e/ou a família formada a partir dele difere da 'norma' e, por isso, não pode ser aceito por aqueles que se enquadram nela. O uso da palavra 'abuso', por sua vez, sugere que, para Feliciano, o anseio do movimento LGBT por respeito se configuraria como uma imposição aos demais cidadãos. Já o enquadramento do relacionamento como 'promiscuidade' reflete o preconceito historicamente direcionado aos homossexuais e à falsa crença de que estes teriam um número maior de parceiros sexuais.

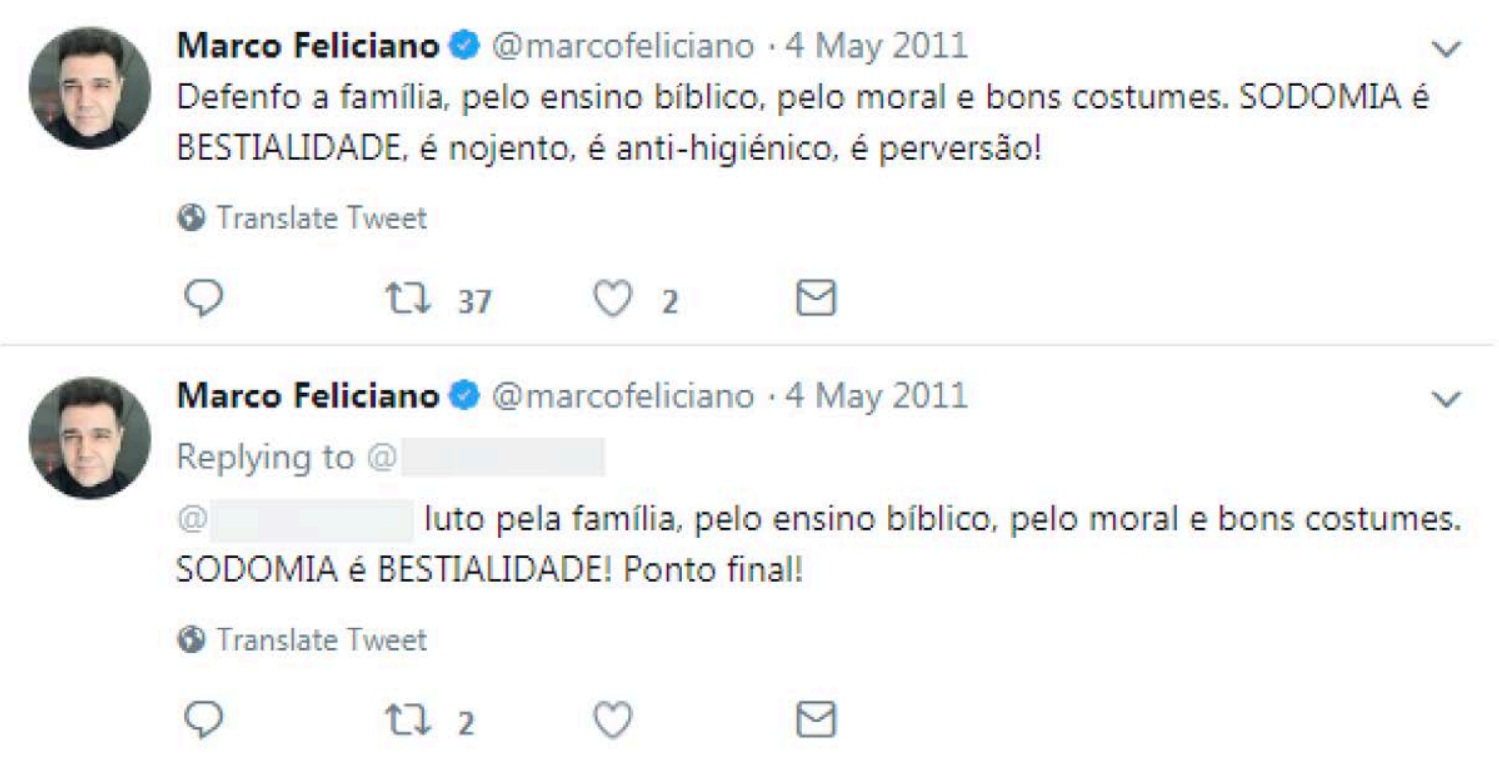

Figura 2 - Marco Feliciano: Posts do dia 4 de maio de 2011

Fonte: Twitter (2018). 
Nos tweets apresentados na Figura 2, o relacionamento homoafetivo é caracterizado pelos termos 'sodomia', 'bestialidade' (estes de cunho religioso), 'nojento', 'anti-higiênico' e 'perversão' (estes de cunho puramente biológico). Ao mesmo tempo, Feliciano justifica seu posicionamento afirmando que sua luta é em defesa do modelo tradicional de família, 'do moral' (sic), do 'ensino bíblico' e dos 'bons costumes'. Os dois tweets apresentados na Figura fazem referência à 'guerra': primeiro com 'luta' e em seguida com 'defesa' - sugerindo que o movimento LGBT e suas pautas são algo a ser combatido. O contexto belicoso pode ser associado à retórica das igrejas neopentecostais, à qual se filia a denominação na qual Feliciano é pastor. A chamada teologia do domínio ${ }^{11}$ fala de uma guerra espiritual entre o bem e o mal, que no contexto reportado por Feliciano estaria configurado entre os que ‘defendem a família’ e os LGBT.

Marco Feliciano @ @marcofeliciano.18 May 2011

Outrossim, tentaremos amanhã, mostrar o FILME DO KIT GAY no plenário, para q todos vejam as aberrações q querem dar as nossas crianças!

6. Translate Tweet

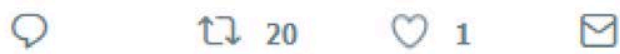

Figura 3 - Marco Feliciano: Post do dia 18 de maio de 2011 Fonte: Twitter (2018).

Esse argumento aparece também na Figura 3, onde os materiais educativos sobre sexualidade e gênero produzidos pelo Governo Federal, pejorativamente apelidados de 'kit gay', são chamados de 'aberrações'. O tweet sugere o medo do pastor de que tais materiais interfiram na formação e educação das crianças - coisa que, para ele e seu grupo, é de responsabilidade dos pais.

Marco Feliciano @marcofeliciano.6 May 2011

@ amor e carinho amigo, me explique a mente de uma

A criança ao perguntarem nome do pai: José e da mãe: João! Como fica?

6 Translate Tweet

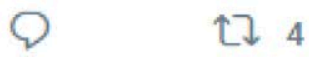

Figura 4 - Marco Feliciano: Post do dia 6 de maio de 2011

Fonte: Twitter (2018).

Marco Feliciano @ @marcofeliciano.21 Oct 2011

Esse menino tentou se castrar! Influencia maldita -> Casal retarda puberdade de filho indeciso sobre o próprio sexo. migre.me/5Y524

6 Translate Tweet

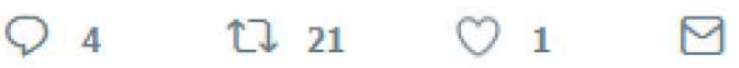

Figura 5 - Marco Feliciano: Post do dia 21 de outubro de 2011 Fonte: Twitter (2018).

O temor ao suposto perigo que os LGBT representam para as crianças também fica evidente nas Figuras 4 e 5, que expressam as percepções de Feliciano em relação ao casamento homossexual e às pessoas trans. 
Na Figura 4, o deputado sugere a um usuário que ter dois pais (ou, implicitamente, duas mães) pode ser nocivo à saúde mental das crianças. Já a Figura 5 é um dos vários tweets nos quais Feliciano divulgou o caso de Tommy, uma criança transgênero cujas mães eram lésbicas. Segundo o pastor, seriam elas a 'influência maldita', as culpadas pelo menino não se identificar com seu sexo biológico, de nascença. Ao compartilhar a notícia com um comentário próprio, o pastor demonstra certo engajamento em 'denunciar' as condutas que seriam 'perversas'; explicita assim, os desvios - e desviantes - morais, protagonizados pelas pessoas LGBT.

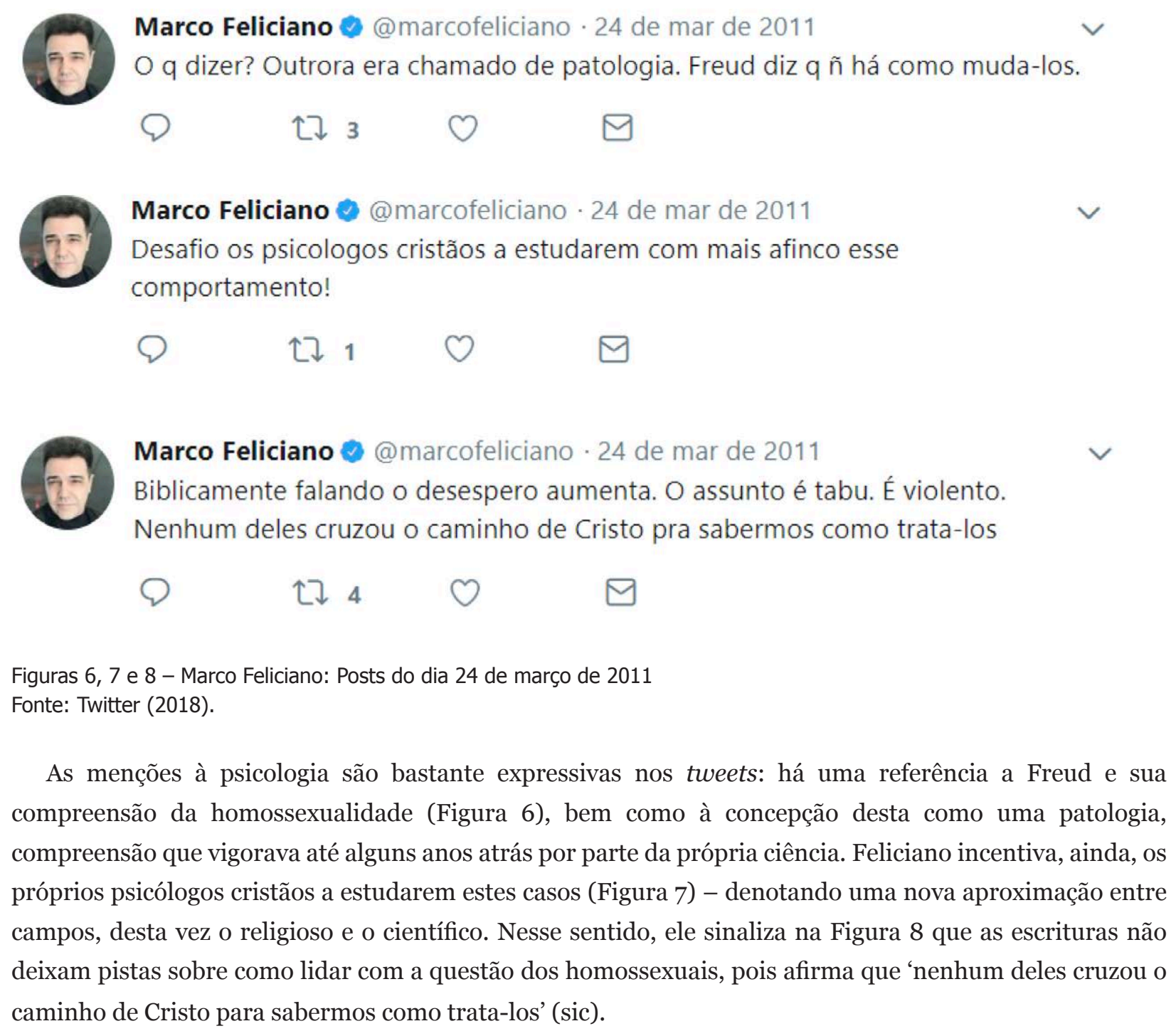


Marco Feliciano @ marcofeliciano.24 de mar de 2011

A angustia de terem trazido a vergonha aos pais. Oremos por eles... Feriram a fôrma familiar. Carregam em si um peso incarregavel! Oremos.

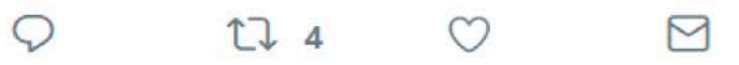

\section{Marco Feliciano @marcofeliciano.24 de mar de 2011}

qdo Falta inteligência ao dialogo usam de baixaria por falta de equilíbrio emocional. A maioria deles carrega o desprezo familiar.

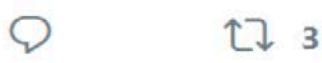

Figura 9 - Marco Feliciano: Posts do dia 24 de março de 2011 Fonte: Twitter (2018).

Marco Feliciano @marcofeliciano.25 de mar de 2011 Ñ quero vê-los ou incita-los a pecar +. E tornar o fardo deles mais pesado do q já é! Boa noite a todos e fiquem sob as Asas do Onipotente!

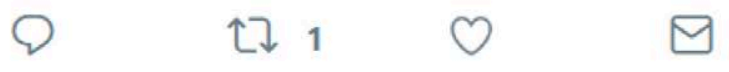

Figura 10 - Marco Feliciano: Post do dia 25 de março de 2011

Fonte: Twitter (2018).

Nas Figuras 9 e 10, por sua vez, o objeto da 'preocupação' de Feliciano são os próprios homossexuais. Segundo o deputado, as pessoas com essa orientação sexual sofrem por envergonhar suas famílias e acabar ignorados pela sociedade por carregar o 'desprezo familiar' (Figura 9). Destaca-se uma 'animalização' das pessoas LGBT nos trechos, ao serem comparados com animais de carga que portam 'fardo' (Figura 10) e 'carregam em si um peso incarregavel' (sic) (Figura 9). Ou seja: Feliciano considera as pessoas LGBT prejudiciais não só para a sociedade como um todo, mas também para si mesmas e suas famílias.

\section{Marco Feliciano @ @marcofeliciano.10 Sep 2011}

veja quem Ataca quem! Vc é gay e só atacou ate agora rss quem fez terrorismo e se posou de vitima foi vc rsss seja feliz amigo

(3) Translate Tweet

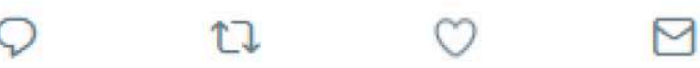

Figura 11 - Marco Feliciano: Post do dia 10 de setembro de 2011

Fonte: Twitter (2018). 
Marco Feliciano @ @arcofeliciano.25 Nov 2011

....insistirem nessa história e confirmar essa imagem. Lutemos hoje pelos nossos

filhos, pela nossa familia, pelas gerações futuras!

6 Translate Tweet

Q 2 七 8

Marco Feliciano @ marcofeliciano.25 Nov 2011

1 grupo nesse país luta $p$ nos retratar como 1 bando de fanático-religiosos cheios de ódio, e esperam a oportunidade para (cont)

6 Translate Tweet

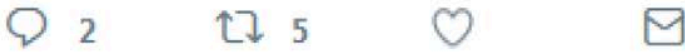

Figura 12 - Marco Feliciano: Posts do dia 25 de novembro de 2011 Fonte: Twitter (2018).

Ao mesmo tempo que alega preocupar-se com as dificuldades vivenciadas pelos LGBT, porém, Feliciano ressalta constantemente o quanto estes 'vitimizam-se' perante à sociedade. Na Figura 11, o pastor vai além: acusa o usuário com o qual debate de fazer 'terrorismo'. Argumenta ainda que o movimento tenta enquadrar as personalidades resistentes às pautas LGBT como intolerantes (Figura 12) quando, segundo ele, são eles próprios [os LGBT] os incapazes de debater. Isso ficou evidente em tweets apresentados anteriormente, nos quais o deputado afirma que os adeptos do movimento utilizam-se de 'baixarias' nas discussões (Figura 9), e é visível na Figura 11, na qual Feliciano acusa o usuário de 'atacá-lo'. Em torno da escolha recorrente de termos como 'ataca' (Figura 11), 'vítima' (Figura 11), 'lutemos' (Figura 12) e 'luta' (Figura 12), temos aqui novamente a presença de uma retórica combativa, que pode ser reportada à teologia do domínio. A Figura 12, por sua vez, traz um movimento discursivo interessante ao descrever quem seríamos 'nós' a partir do olhar 'deles'. Feliciano afirma nesse tweet que os LGBT enxergariam os que se alinham ao seu pensamento como ‘1 bando de fanático-religiosos cheios de ódio’ (sic).

\section{Marco Feliciano @marcofeliciano.24 de mar de 2011} Homossexualidade ou homossexualismo, ambos os termos se aplicam a pessoas q se relacionam a outras do mesmo sexo.

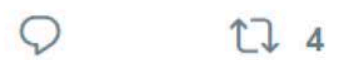

Figura 13 - Marco Feliciano: Post do dia 24 de março de 2011 Fonte: Twitter (2018).

A Figura 13 faz referência ao desinteresse em diferenciar 'homossexualidade' de 'homossexualismo' expresso pelo pastor. Termo que caiu em desuso justamente por remeter à patologização, o uso do termo 'homossexualismo' evidencia o desdém de Marco Feliciano para com os LGBT. Como vimos em postagens acima nas quais o pastor se reporta às identidades trans, toda a pluralidade de identidades de gênero e orientação sexual do movimento LGBT é reduzida a uma única representação.

Conforme observamos anteriormente, a compreensão dos corpos enquanto 'espécie', caracterizada na ideia foucaultiana de "governo da população", justifica a redução identitária proposta por Feliciano. A ideia apresentada de um 'nós' contra 'eles' alinha-se à perspectiva de pensar nas relações de poder que ligam 
os indivíduos associados a essas representações. O ‘eles' congrega o 'corpo-espécie' dos LGBT, despidos de suas complexidades e compreendidos enquanto corpos sacros, passíveis de ser aniquilados pelo poder soberano exercido pelo 'nós', aqueles que exercem o poder soberano.

Recapitulando as designações acima analisadas, podemos agrupá-las em três grandes regiões de sentido, que correspondem a categorias que sintetizam a forma como as postagens expressam o ódio biopolítico. As principais designações encontram-se sintetizadas no quadro abaixo (Quadro 1).

Quadro 1 - Categorias de ódio biopolítico e designações dos LGBT associadas

\begin{tabular}{|l|l|}
\hline Categorias & Designações \\
\hline a) patologização & Sodomia, perversão, tabu, distorção, comportamento, aberrações \\
\hline b) inferiorização & Vergonha, pena, oprimidos, ignorados, desprezados, influência maldita \\
\hline c) animalização & Bestialidade, promiscuidade, nojento, anti-higiênico, fardo, raivosos, carregam peso \\
\hline
\end{tabular}

Fonte: As autoras (2019).

Na primeira, a de patologização, compreendemos os termos que fazem referência aos LGBT como uma espécie de indivíduos doentes, passíveis de contagiar a sociedade com suas características supostamente prejudiciais. Daí vem a concepção do 'perigo' que o convívio com LGBT pode trazer para a infância, e que Feliciano resgata como um argumento justificando sua contrariedade à adoção de crianças por casais homoafetivos. A segunda delas, a inferiorização, traz as designações dos LGBT que os diminuem em importância, concebendo-os como indivíduos desprezíveis ou passíveis de pena. Já a animalização faz menção ao movimento de destituir o caráter de bios da vida dos LGBT, reduzindo-os à dimensão de vida nua. As três categorias pelas quais se expressa o ódio biopolítico se dão, portanto, a partir do exercício de um dispositivo racista que irá exercer seu poder discursivo por meio dos mecanismos de normalização e da exposição à morte. Aquele que detém o saber-poder dita através da normalização os limites entre o aceitável e o patológico, eliminando a vida daquela que é considerada a 'raça ruim'.

\section{Considerações finais}

No que tange às pautas ligadas à sexualidade e ao gênero, as designações dos LGBT exploradas pelo pastor em suas postagens no Twitter configuram-se, em grande parte das vezes, como o que denominamos de 'ódio biopolítico'. É este o sentimento que identificamos nos posicionamentos de Feliciano em sua contrariedade às pautas LGBT: características que são inerentes aos sujeitos são tomadas como objeto e destino do ódio do deputado. Por não estarem de acordo com a 'norma', as pessoas LGBT são tidas como prejudiciais à manutenção da mesma, o que faz com que o pastor e os seus apoiadores busquem combatê-las discursivamente - utilizando-se, vale dizer, de empreendimentos morais e controle sobre as condutas privadas.

Podemos afirmar que o controle ou o desejo de controle sobre o comportamento privado alheio configurase, indubitavelmente, como uma característica do ativismo moral desempenhado por Marco Feliciano em seu Twitter. Tendo em vista que o objetivo maior de suas ações é de tornar universais os valores que lhes são próprios, inferimos uma necessidade no sentido de 'normalizar' as condutas que lhes parecem 'desviantes'. Para isso, também ressaltamos o caráter incessante (e dialético) de trabalho dos criadores e impositores de regras, uma vez que ‘dependem' desses desvios para conquistarem legitimidade e reconhecimento social, sendo fundamentadas em finalidades biopolíticas.

Ao explorarmos as dimensões institucionais que suportam as inferências religiosas, políticas e científicas designadas pelo pastor e deputado em seus comentários no Twitter, compartilhamos de leituras que relacionam a ascensão do neoconservardorismo brasileiro ao ativismo digital realizado por lideranças 
evangélicas atualmente. Na medida em que se classificam práticas e condutas 'desviantes', julga-se o que é 'normal' ou 'naturalizado' (seja pela Bíblia ou pelo código jurídico-civil). Neste caso, especificamos questões e pautas políticas trabalhadas sob a perspectiva da igualdade de gênero e sexualidade, em que presenciamos um grupo social [LGBT] ser explicitamente taxado enquanto 'ameaça' e 'fardo pesado' pela mera condição distinta em que se sentem e se apresentam à 'norma' social (heterossexual e cisgênera).

Buscamos, portanto, delinear como essas divergências são, cada vez mais, denunciadas a partir de comentários racistas e odiosos, os quais, numa escala de visibilidade e circulação de discursos em midiatização, ressignificam seu alcance e sentido em contato com os milhares de usuários da rede. No momento em que dispomos dessas linhas teóricas, empíricas e metodológicas, compreendemos a contemporaneidade do exercício da biopolítica em nossa tão recente redemocratização.

Dessa maneira, reconhecemos que, apesar da expansão e de todas as conquistas já alcançadas pelo movimento LGBT no Brasil, ainda existem muitos avanços necessários para se combater a discriminação e o ódio materializados em discursos e condutas violentas contra esses indivíduos e grupos considerados 'desviantes'. Ao vislumbrarmos uma verdadeira consolidação de princípios democráticos (expressos em nossa Constituição), torna-se relevante analisarmos os sentidos das manifestações compartilhadas no ambiente midiatizado, em que também se disputam opiniões sobre as políticas públicas e a implementação de novas leis. Assim, dimensionando e caracterizando o intrínseco racismo experimentado em nossa atual vivência biopolítica, podemos entender como os discursos conservadores ganham força e apoio por meio de um controle disciplinar e 'normalizante' dos corpos e condutas humanas.

Apesar de os indícios destacarem um certo pessimismo em análise, a pretensão é de que, ao identificar as marcas dessa biopolítica, possamos, de forma mais propositiva, defender e garantir a proteção de todas as vidas humanas. Afinal, a conhecida 'Constituição Cidadã', em vigência em nosso país desde 1988, entende o fundamento da dignidade humana e a defesa dos direitos humanos enquanto princípios formadores de nosso Estado democrático.

\section{Referências}

1. Prandi R, Santos RW. Quem tem medo da bancada evangélica? Posições sobre moralidade e política no eleitorado brasileiro, no Congresso Nacional e na Frente Parlamentar Evangélica. Rev Tempo Social [Internet]. 2017 ago. [citado em 2017 ago. 07];29(2):187-213. Disponível em: http://www.revistas.usp. br/ts/article/view/110052/130984.

2. Pierucci AF. Representantes de Deus em Brasília: a bancada evangélica na constituinte. Ci Soc Hoje. 1989;(11)104-32.

3. Sodré M. Antropológica do espelho: uma teoria da comunicação linear e em rede. Petrópolis: Vozes; 2010.

4. $\quad$ Foucault M. História da sexualidade I: a vontade de saber. Rio de Janeiro: Edições Graal; 1988. Foucault M. Direito de morte e poder sobre a vida; p. 125-49.

5. Foucault M. Em defesa da sociedade: curso no Collège de France (1975-1976). São Paulo: Martins Fontes; 1999. Aula de 17 de março de 1976; p. 285-315.

6. $\quad$ Agamben G. Homo sacer: o poder soberano e a vida nua I. Belo Horizonte: Editora UFMG; 2007.

7. Pelbart PP. Biopolítica. In: Vida capital: ensaios de biopolítica. São Paulo: Iluminuras; 2009.

8. Bazzicalupo L. Biopolítica: um mapa conceitual. São Leopoldo: Unisinos; 2017.

9. Maingueneau D. Análise de textos de comunicação. São Paulo: Cortez; 2008.

10. Orlandi EP. Análise de discurso: princípios e procedimentos. Campinas: Pontes; 1999.

11. Vital da Cunha C, Lopes PVL. Religião e política: uma análise da atuação de parlamentares evangélicos sobre direitos das mulheres e LGBTs no Brasil. Rio de Janeiro: Fundação Heinrich Böll; 2012. 